\title{
Directrices en la aplicación de la guía de práctica clínica en la lumbalgia
}

\author{
Guidelines on the application of the clinical practice guideline on low back pain
}

José María Jiménez-Ávila* ${ }^{*}$, Erik Noe Rubio-Flores ${ }^{*}$ Arelhi Catalina González-Cisneros², Jaime Eduardo Guzmán-Pantoja ${ }^{1}$ y Elsa Armida Gutiérrez-Román ${ }^{1}$

${ }^{1}$ Centro Médico Nacional de Occidente Hospital, Instituto Mexicano del Seguro Social; ${ }^{2}$ Escuela de Medicina del Instituto Tecnológico de Monterrey. Guadalajara, Jal., México

\section{Resumen}

Introducción: La lumbalgia se define como el dolor en el área de la porción superior de T12 e inferior al pliegue de los glúteos, y además limitación funcional. La prevalencia de la lumbalgia va aumentando un $11.4 \%$ por año. En México no se siguen las guías de práctica clínica en el manejo de las lumbalgias, por lo que es importante sistematizar la atención médica para eficientizar, ya que cada vez los recursos son más escasos. El médico de primer nivel debe conocer los criterios de referencia según la necesidad del paciente. Se realizan una anamnesis incompleta, una exploración física inadecuada, una mala interpretación de los estudios de gabinete, un diagnóstico equivocado, un manejo ineficaz y la referencia a segundo o tercer nivel no justificada. Objetivo: Proporcionar recomendaciones para la realización del diagnóstico sindrómico, el manejo de los adultos portadores de lumbalgia y su correcta referencia. La aplicación de las guías de práctica clínica para el síndrome doloroso lumbar consta de una evaluación del paciente a manera de "verificación", en la que se evalúan determinados signos o síntomas, con un total de 37 ítems por calificar, incluyendo los apartados de sintomatología clínica, radiografía anteroposterior, radiografía lateral, resonancia magnética sagital (opcional) y axial (opcional), y tipo de dolor. Estos datos orientan de manera rápida y sencilla, desde el primer contacto, a un diagnóstico sindrómico en el paciente con lumbalgia.

PALABRAS CLAVE: Guías clínicas. Lumbalgia. Aplicación. Columna.

\begin{abstract}
Introduction: Low back pain is defined as pain in the upper portion of T12 and below the crease of the buttocks and functional limitation. The prevalence of low back pain gradually increases $11.4 \%$ per year. In Mexico, the clinical practice guidelines are not followed in handling low back pain, so it is important to systematize medical care more efficient, since resources are scarce. The first level doctor must meet the benchmarks according to patient need, an incomplete anamnesis is performed, inadequate physical examination, misinterpretation of clinical studies, misdiagnosis, ineffective management, and reference to second or third level not justified. Objective: To provide recommendations for the implementation of syndromic diagnosis, management of adult carriers of low back pain, and correct reference. Implementation of clinical practice guidelines for low back pain syndrome consists of an assessment of the patient by way of "verification", which evaluates certain signs of symptoms, with a total of 37 items for rating, including the sections of clinical symptomatology, AP X-ray, lateral X-ray, sagittal (optional) and axial magnetic resonance imaging (optional), and pain type. Oriented data quickly and easily, from first contact to a syndromic diagnosis in patients with low back pain.
\end{abstract}

KEY WORDS: Guidelines. Low back pain. Application. Spine.

\author{
Correspondencia: \\ *José María Jiménez Ávila \\ Belisario Domínguez No. 1000 \\ Col. Independencia \\ C.P. 44340, Guadalajara, Jal., México \\ E-mail: josemajimeneza@ hotmail.com
}

Fecha de recepción: 23-07-2017

Fecha de aceptación: 14-02-2018

DOI://dx.doi.org/10.24875/CIRU.M18000013
Cir Cir. 2018;86:29-37

Disponible en PubMed www.cirugiaycirujanos.com 


\section{Introducción}

La lumbalgia se define como dolor o malestar en un área alrededor de la porción superior de T12 e inferior al pliegue de los glúteos, junto con limitación funcional. Cabe destacar que esta definición no aplica a una lumbalgia en específico y es independiente de la causa que le dio origen (Fig. 1).

La lumbalgia es la segunda causa más frecuente de consulta médica en el primer nivel de atención; entre el 60 y el $80 \%$ de la población experimentará este problema en algún momento de su vida, lo que condicionará el $40 \%$ de todas las ausencias de trabajo, disminuyendo la productividad de los afectados. La prevalencia de este problema de salud va aumentando un $11.4 \%$ por año, por lo que es una patología que se presenta muy a menudo en los servicios de salud'.

Existe un problema que repercute en la profesionalización del diagnóstico de la patología de columna, ya que no se siguen criterios ni las llamadas guías de práctica clínica (GPC) en el manejo de la patología de columna. El diagnóstico y el tratamiento del dolor lumbar son complicados por la dificultad en la identificación de la etiología y por lo inespecífico del dolor en muchas ocasiones. Es importante sistematizar la atención médica, ya que cada vez los recursos son menos, por lo que se tiene que eficientizar cada uno de los procesos en la atención de la etiología de la lumbalgia.

Algunos estudios han reportado que más del $80 \%$ de los médicos refieren a sus pacientes para la toma de placas radiográficas cuando existe dolor de espalda recurrente, y en más del $70 \%$ cuando los pacientes presentan por primera vez un episodio de lumbalgia. La mayoría de los pacientes que consultan a su médico familiar pueden mejorar dentro de pocas semanas, y solo una minoría desarrollará dolor de espalda crónico. Se ha encontrado relación entre el índice de masa corporal y la prevalencia de lumbalgia ${ }^{2}$, y en casos muy raros se pueden identificar causas graves con déficit neurológico o neoplasias.

Analizando el panorama nacional y su emisión de incapacidades, en algunas instituciones de atención médica pública, las cuales abarcan el $93 \%$ de la población atendida, en conjunto proporcionaron $27.8 \mathrm{mi}-$ llones de días de incapacidad laboral en el año 2007, lo que se traduce en 5.8 miles de millones de pesos mexicanos $^{3}$.

Lo anterior refleja la gravedad del problema, la frecuencia con que se presenta y el costo que causa, lo que repercute en el gasto de salud, y al momento de hacer el análisis de la fisiopatología de la enfermedad encontramos puntos de intervención en la atención médica recibida en el primer nivel de atención.

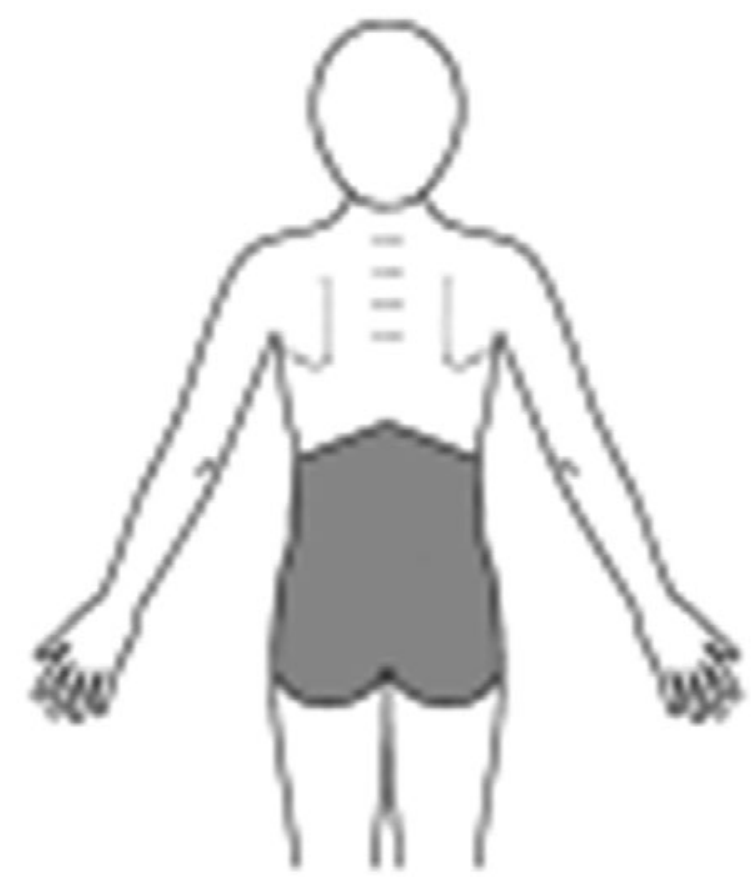

Figura 1. Área topográfica considerada como región lumbar. 
Tabla 1. Patologías de la región lumbar según su etiología

\begin{tabular}{llc}
\hline Mecánica & No mecánica & Visceral \\
\hline Tensión lumbar o torcedura: & Neoplasia: & Órganos pélvicos: \\
- Enfermedad degenerativa & - Carcinoma metastásico & - Prostatitis \\
- Discos (espondilosis) & - Mieloma múltiple & - Endometritis \\
- Superficies articulares & - Linfoma y leucemia & - Enfermedad inflamatoria pélvica crónica \\
- Hiperostosis difusa idiopática & - Tumores del cordón espinal & Enfermedad renal: \\
Espondilosis & - Tumores retroperitoneales & - Nefrolitiasis \\
Espondilolistesis & Infección: & - Pielonefritis \\
Hernia de disco & - Osteomielitis & - Absceso perinefrítico \\
Estenosis espinal & - Discitis séptica & Enfermedad vascular: \\
Osteoporosis con fractura por & - Abscesos paraespinales o epidurales & - Aneurisma de la aorta abdominal \\
compresión & - Endocarditis & - Enfermedad aortoilíaca \\
Fracturas & Enfermedades reumáticas inflamatorias: & Enfermedad gastrointestinal: \\
Enfermedad congénita: & - Espondilitis anquilosante & - Pancreatitis \\
- Cifosis grave & - Síndrome de Reiter & - Colecistitis \\
- Escoliosis grave & - Espondilitis psoriásica & - Perforación intestinal \\
- Enfermedad de Paget & - Enfermedad inflamatoria intestinal & \\
& - Polimialgia reumática & \\
\hline
\end{tabular}

El médico familiar tiene un gran compromiso en hacer una detección rápida, precisa, y si es posible, un manejo médico oportuno desde el primer contacto que se tenga con el paciente con lumbalgia, así como de igual forma debe conocer los criterios adecuados de referencia al segundo o tercer nivel, según la necesidad real del paciente, ya que en la actualidad se ha venido presentando una mala práctica del médico de primer contacto, quien en ocasiones realiza una anamnesis incompleta, una exploración física inadecuada, un uso incorrecto o una mala interpretación de los estudios de gabinete, un diagnóstico equivocado, un manejo ineficaz y la referencia a segundo o tercer nivel no justificada, esto a pesar de la existencia de las GPC.

Es sabido que la lumbalgia puede clasificarse, de acuerdo con el tiempo de evolución, como aguda (el dolor dura menos de 2 a 4 semanas), subaguda (el dolor dura entre 4 y 12 semanas) o crónica (los síntomas duran más de 12 semanas).

El dolor lumbar se ha clasificado según su etiología, de manera general, en tres diferentes tipos: mecánico, no mecánico y visceral. Los más frecuentes se presentan en la tabla 1.

Toda esta información es importante para llegar a un diagnóstico preciso, y para poderlo lograr se requiere que se apliquen principios propedéuticos fundamentales para realizar un diagnóstico topográfico, un diagnóstico sindrómico y un diagnóstico etiológico; además, si recordamos que la medicina no es una ciencia exacta, tendremos presente siempre un cuarto diagnóstico, que será el diferencial.

Para tal efecto se establecen estas directrices en la aplicación de las GPC, cuyo objetivo es proporcionar al médico del primer nivel de atención médica los datos, la metodología y las herramientas necesarias para orientarlo en las decisiones clínicas para pacientes con lumbalgia, enfocadas en el diagnóstico certero, en el manejo específico y la detección de las banderas rojas, y para conocer los adecuados criterios de referencia a otros niveles de atención y evitar realizar diagnósticos falsos positivos, o bien, lo que puede ser más grave, diagnósticos falsos negativos.

\section{Objetivo}

Comprender los criterios necesarios para definir la lumbalgia, con la finalidad de diagnosticar su etiología.

\section{Usuarios}

Médico familiar, medicina física y rehabilitación, traumatología y ortopedia, urgencias médicas, médico general y todo el personal de salud involucrado en la atención de primer nivel de pacientes con lumbalgia.

\section{Población blanco}

Hombres y mujeres mayores de 16 años con dolor en la región lumbar.

\section{Selección de la evidencia}

Las palabras clave de búsqueda fueron lumbalgia, lumbago, dolor de espalda baja, dolor de espalda, atención primer nivel, GPC y guía de práctica clínica, en fuentes de información que databan del año 2000 al año 2015. Se consultaron las bases de datos 
Cochrane Library y Ebsco host research databases. Se incluyeron para la construcción de esta guía una revisión de temas y tres artículos de revisión. Se buscó en la base de datos Medline y se tomaron cinco ensayos clínicos publicados dentro de esas fechas.

El material localizado fue analizado por los integrantes del grupo constructor de la guía, y su inclusión final se realizó por discusión entre los participantes, utilizando los criterios de las guías para los usuarios de la literatura médica publicados en JAMA entre 2000 y 2015.

\section{Definiciones operativas}

- Lumbalgia: dolor o malestar en la zona lumbar, localizado entre el borde inferior de las últimas costillas y el pliegue inferior de la zona glútea, con o sin irradiación a una o ambas piernas, y que compromete estructuras osteomusculares y ligamentarias, con o sin limitación funcional que dificulta las actividades de la vida diaria y que puede causar ausentismo laboral.

- Lumbalgia aguda inespecífica: es lo que se conoce como «dolor común». Sus características fundamentales son:

- Paciente entre 20 y 55 años.

- Dolor en la región lumbosacra, los glúteos y los muslos.

- Dolor de características mecánicas.

- Buen estado general de la persona afectada.

- Lumbalgia crónica: lumbalgia que se presenta por un periodo de tiempo mayor de 12 semanas.

- Ciática: dolor irradiado hacia la parte posterior de la pierna en la distribución del nervio ciático, que sugiere compromiso mecánico o inflamatorio.

- Radiculopatía: disfunción de una raíz nerviosa asociada con dolor, déficit sensorial, calambres o disminución de los reflejos osteotendinosos en la distribución de un nervio específico.

- Maniobra de Lassegue: prueba clínica que se realiza con el paciente en decúbito dorsal, flexionando la cadera de la extremidad afectada, con la rodilla en extensión, de manera progresiva y lenta. Se considera positivo en caso de dolor agudo irradiado hacia la pierna en la flexión de cadera/pelvis entre 30 y 60 grados.

\section{Método}

- Realización del diagnóstico topográfico (lumbalgia) tomando en cuenta los signos y síntomas referidos por el paciente (apegados al formato Anexo 1).

- Solicitud de radiografías simples y exámenes de laboratorio, tratando de identificar el tipo de dolor y datos de inestabilidad (Anexo 1).

- Realización del diagnóstico sindrómico para su envío a la unidad de segundo nivel.

- Confirmación del diagnóstico sindrómico mediante estudios de gabinete, (tomografía computarizada y resonancia magnética), basados en criterios de inestabilidad y de compromiso neurológico.

- Realización del diagnóstico etiológico e identificación de signos y síntomas (bandera roja) para su envío a la unidad de tercer nivel bajo cuatro posibles acciones diagnósticas:

- Traumático (color verde). Causa un dolor mecánico: se exacerba con la actividad física y localizado en la región lumbar.

- Degenerativo (color rojo). Provoca dolor radicular: se irradia hasta la punta del dedo gordo del pie, disestesias.

- Síndrome de destrucción vertebral (color azul). Causa dolor nocturno: se incrementa por la noche.

- Deformidades (color anaranjado). Causa dolor neuropático: por lesión directa de un nervio y puede afectar las extremidades.

Una vez resuelto el motivo de consulta, esta será bidireccional mediante una correcta contrarreferencia, esto es, los pacientes posquirúrgicos podrán ser enviados de tercero o segundo nivel cuando así lo requieran, y a su vez, cuando sean contrarreferidos de segundo a primer nivel para la correcta actuación del médico de primer nivel, permitiendo que el médico familiar funcione como estabilizador de la atención medica de los tres niveles.

\section{Anotaciones al algoritmo}

\section{Diagnóstico}

El médico de primer nivel debe realizar una historia y una exploración física orientadas, que le permitan ubicar al paciente con dolor bajo de espalda inespecífico, dolor lumbar potencialmente asociado con radiculopatia o dolor lumbar potencialmente asociado con enfermedad sistémica especifica ${ }^{4}$. 


\section{Exploración física y clasificación}

Se recomienda realizar un interrogatorio y una exploración física orientada. Poner especial atención en la edad del paciente, el sexo, la ocupación, el tiempo de evolución (aguda, < 6 semanas; subaguda, entre 6 y 12 semanas; crónica, $>12$ semanas) y el tipo de dolor (mecánico o inflamatorio), e investigar datos de compromiso neurológico.

La presencia de paresia aporta una alta especificidad (93\%) al diagnóstico de compresión radicular, por lo que su presencia prácticamente confirma el diagnóstico ${ }^{5}$.

La retención urinaria (sensibilidad del $90 \%$ y especificidad del $95 \%$ ) y la anestesia en silla de montar son los signos de mayor utilidad en el diagnóstico de la cauda equina ${ }^{5}$.

\section{Bandera roja}

La exploración física debe ser intencionada con el fin de detectar la presencia de los signos de bandera roja en la lumbalgia:

- Edad de inicio antes de los 20 años o después de los 55 años.

- Antecedente reciente de traumatismo importante.

- Dolor constante, progresivo, no mecánico (no se alivia con el reposo).

- Dolor que empeora de noche.

- Dolor torácico.

- Antecedente de neoplasias malignas (o sospecha).

- Uso prolongado de corticoesteroides.

- Abuso de drogas ilícitas, inmunosupresión o infección por el virus de la inmunodeficiencia humana.

- Malestar general.

- Pérdida no explicada de peso.

- Deformidad estructural.

- Fiebre, infección urinaria reciente o herida penetrante cerca de la columna.

- Pérdida sensitiva o motora progresiva.

- Antecedente de osteoporosis.

- Falta de mejoría después de 6 semanas de manejo conservador apropiado.

- Anestesia en silla de montar, ciática bilateral, dificultad para orinar 0 incontinencia fecal ${ }^{6}$.

\section{Estudios de imagen}

Generalmente, las radiografías de columna lumbar anteroposterior y lateral son útiles en la lumbalgia aguda para descartar alguna patología oculta relacionada con la parte estructural de la columna vertebral.

La radiografía de columna tiene su indicación en el paciente con lumbalgia y sospecha de patología grave, como cáncer o infección. Cuando en la anamnesis y la exploración física se identifiquen signos de alarma, se recomienda solicitar proyecciones anteroposterior y lateral con el paciente de pie y sin calzado. En la radiografía se deberá buscar de forma intencionada escoliosis, alteración en las curvaturas, forma de las vértebras, fracturas, listesis, espacios intervertebrales, disminución del foramen oval, presencia de osteofitos, deferencia en la altura de las crestas iliacas y alteración de los tejidos blandos.

No se recomienda realizar pruebas de imagen (radiografía, resonancia magnética y tomografía computarizada) en pacientes con dolor lumbar agudo sin signos de alarma ${ }^{7}$.

\section{Tratamiento farmacológico}

Se recomienda que ante un paciente con lumbalgia sin respuesta al tratamiento después de 4-6 semanas de evolución se realice una reevaluación de los datos clínicos, los factores ocupacionales y el apego al tratamiento, así como una búsqueda intencionada de signos de alarma y una evaluación de la utilidad de los estudios de imagen.

Se recomiendan los antiinflamatorios no esteroideos (AINE) como primera elección en el tratamiento de la lumbalgia aguda y subaguda inespecífica, por su mejor perfil de riesgo/beneficio. Se recomienda, previo al inicio del tratamiento farmacológico, tomar en consideración los siguientes aspectos: edad del paciente, comorbilidad, dieta, interacciones farmacológicas, y función cardiovascular y renal; y prescripción de protectores de la mucosa gástrica con el fin de prevenir complicaciones asociadas con la administración de AINE.

En el tratamiento de la lumbalgia crónica se recomienda asociar al paracetamol un AINE, evaluando la respuesta individualizada en el paciente, pero no se recomienda el uso de AINE por más de 4 semanas.

No se recomienda la administración de opiáceos en la lumbalgia aguda como tratamiento inicial.

No se recomienda la indicación de antidepresivos en el manejo de la lumbalgia aguda.

No hay evidencia de que los esteroides por vía sistémica sean eficaces en el tratamiento del dolor lumbar inespecífico 
No se recomiendan infiltraciones epidurales, facetarias, en puntos gatillo ni intradiscales en las personas con dolor lumbar subagudo o crónico inespecífico.

No hay evidencia de que la administración de vitamina B sea eficaz para el tratamiento del dolor lumbar inespecífico?

\section{Tratamiento no farmacológico}

Hay evidencia de que proporcionar información al paciente con lumbalgia produce una mejoría más temprana, reduce el número de visitas al médico y mejora el estado funcional.

Hay que proporcionar educación acerca de los factores agravantes, la evolución y el tiempo estimado de mejoría, lo que permite acelerar la recuperación en pacientes con lumbalgia aguda y prevenir el desarrollo de lumbalgia crónica.

La meta primaria de la rehabilitación en las personas con dolor lumbar agudo es tratar de disminuir o eliminar el dolor, procurar la reincorporación a las actividades y el trabajo, prevenir el desacondicionamiento, la discapacidad y la tendencia a la cronicidad, y evitar conductas incorrectas e innecesarias.

Existe evidencia de que los pacientes que mantienen un estado activo y continúan con actividades normales de la vida diaria, incluyendo el trabajo, tienen una recuperación más temprana de los síntomas y reducen la discapacidad.

En las personas con dolor lumbar agudo, el reposo por más de 2-3 días es inefectivo e incluso dañino.

No se recomienda reposo en cama; si la intensidad del dolor lo requiere, será de la menor duración posible.

El calor local produce una disminución del dolor y de la incapacidad a corto plazo en la lumbalgia aguda y subaguda. La aplicación de frío local no se recomienda en la lumbalgia aguda y crónica.

Es importante recomendar al paciente interrumpir cualquier actividad o ejercicio que cause aumento de los síntomas. Los programas de ejercicio aeróbico con mínimo esfuerzo lumbar (caminar, bicicleta, nadar) pueden iniciarse en las primeras 2 semanas en la mayoría de los pacientes con lumbalgia aguda.

Los ejercicios de fortalecimiento para los músculos del tronco, especialmente los extensores de la columna, con incremento gradual, pueden beneficiar a los pacientes con lumbalgia aguda ${ }^{7}$ (Fig. 2).

\section{Referencias al segundo nivel de atención}

- Datos de síndrome de cauda equina.

- Déficit neurológico.

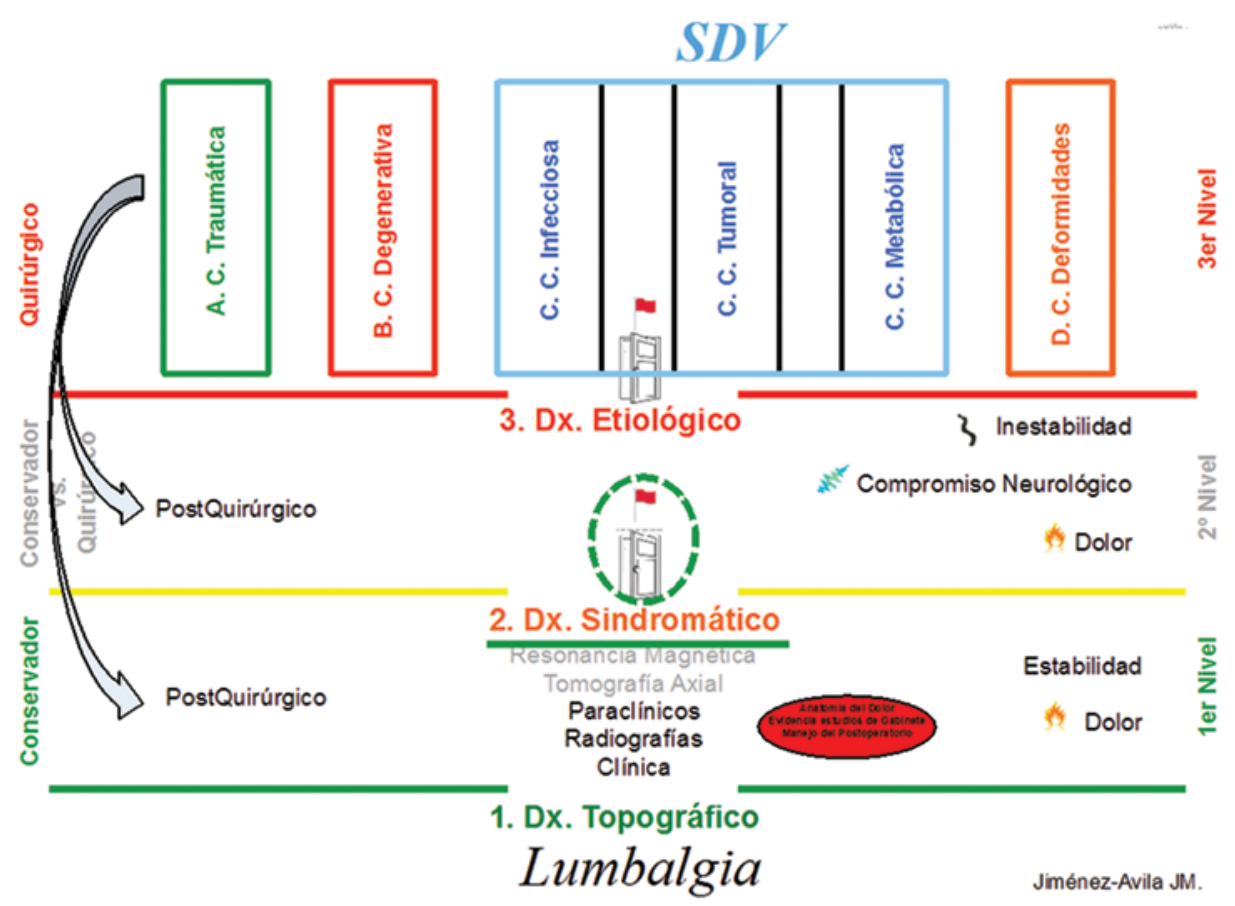

Figura 2. Algoritmo para la referencia y la contrarreferencia del paciente con lumbalgia. 
Tabla 2. Recomendaciones de reincorporación laboral para el paciente con dolor lumbar agudo

\begin{tabular}{|c|c|c|c|c|}
\hline Nivel de actividad & $\begin{array}{l}\text { Dolor lumbar } \\
\text { moderado }\end{array}$ & $\begin{array}{l}\text { Dolor lumbar } \\
\text { intenso }\end{array}$ & Ciática & Modificaciones típicas \\
\hline $\begin{array}{l}\text { Trabajo ligero } \\
\text { (sentado, levantar y cargar hasta } 9 \mathrm{~kg} \text { ) }\end{array}$ & 0 días & 0-3 días & 2-5 días & $\begin{array}{l}\text { No levantar más de } 2.25 \mathrm{~kg} \text { tres veces por hora } \\
\text { No permanecer sentado, de pie o caminando } \sin \\
\text { una pausa de } 5 \text { minutos cada hora }\end{array}$ \\
\hline $\begin{array}{l}\text { Trabajo moderado (estar de pie, caminar, } \\
\text { flexionarse, cargar hasta } 22.5 \mathrm{~kg} \text { ) }\end{array}$ & & 14-17 días & 21 días & \\
\hline $\begin{array}{l}\text { Trabajo pesado } \\
\text { (caminar, girar o agacharse, cargar hasta } \\
45 \mathrm{~kg} \text { ) }\end{array}$ & 7-10 días & 35 días & 35 días & $\begin{array}{l}\text { No levantar más de } 11.25 \mathrm{~kg} 15 \text { veces por hora, } \\
\text { no permanecer sentado, de pie o caminando sin } \\
\text { una pausa de } 10 \text { minutos cada hora } \\
\text { Conducir automóvil o camioneta hasta } 6 \text { horas } \\
\text { por día, manejar vehículos o equipo pesado por } \\
\text { más de } 4 \text { horas al día }\end{array}$ \\
\hline
\end{tabular}

Los tiempos para la reincorporación laboral completa pueden variar de acuerdo con la gravedad y el tipo de trabajo, y son típicos para edades de 35 a 55 años. Los tiempos para trabajadores más jóvenes son aproximadamente un $20-30 \%$ más cortos 8 .

- Características inflamatorias, artritis, elevación de los reactantes de fase aguda y alteraciones radiográficas de columna dorsolumbar o sacroilíacas.

- Lumbalgia crónica.

- Más de 6 semanas de incapacidad.

- Duda diagnóstica?.

\section{Vigilancia y seguimiento}

Los episodios de dolor mejoran rápidamente, pero la persistencia de síntomas residuales es frecuente.

En pacientes con dolor lumbar agudo, subagudo o crónico se recomienda continuar con las actividades de la vida diaria, incluyendo la incorporación al trabajo siempre que el dolor lo permita.

En el paciente con lumbalgia aguda inespecífica se recomienda una consulta a las 2-4 semanas de instituido el tratamiento, con la finalidad de evaluar la respuesta terapéutica.

Dentro de las intervenciones de prevención probablemente efectivas se incluyen actividad física, realizar ejercicios aeróbicos, fortalecimiento de músculos extensores de la espalda y evaluación de los factores psicosociales y de la satisfacción laboral7

\section{Incapacidades}

Tiempo estimado de recuperación y días de incapacidad cuando proceda. Se recomienda tener en consideración, antes de determinar los días de incapacidad en un paciente, los siguientes factores predictores de cronicidad: episodios previos de dolor lumbar, edad $>50$ años, dolor irradiado, presencia de signo de Lassegue positivo, incapacidad producida por el dolor al inicio del episodio, depresión y aislamiento social o alta demanda física en el trabajo (Tabla 2).

No se recomienda otorgar una incapacidad de más de 2 días a los pacientes con lumbalgia aguda inespecífica.

\section{Discusión}

Una de las patologías que tiene mayor incidencia en México y en Latinoamérica y que se refleja en ausencia laboral es la lumbalgia. Su diagnóstico sindrómico que incluye una variedad importante de afecciones, que van desde el dolor generado por un sobreesfuerzo mecánico hasta patologías de índole estructural que requieren un manejo quirúrgico por una unidad de alta especialidad. Por ello, es de suma importancia que cada nivel de atención tenga claridad en la evidencia que debe recabar con el objeto de realizar un dianóstico etiológico eficaz y evitar el alargamiento de la atención, o bien el envío oportuno, en los casos en que la patología lumbar esté asociada a problemas relacionados con traumatismos, infecciones, tumores o afecciones de tipo metabólico, evitando hacer diagnósticos falsos positivos o falsos negativos.

Existen dos puntos que deben remarcarse para iniciar el proceso de la atención de un paciente con lumbalgia: la inestabilidad y el compromiso neurológico. Estos serán los causantes de la sintomatología dolorosa, motivo de consulta de la mayoría de los pacientes, y son de suma importancia para la toma de decisiones desde el punto de vista quirúrgico.

Es necesario recalcar la relevancia que tiene la exploración física dirigida desde el médico de primer nivel, identificando los denominados signos de «bandera roja», mismos que permiten orientar el diagnóstico e identificar el tipo de lumbalgia. 
Como última recomendación para fortalecer la evidencia clínica, debe identificarse de manera dirigida la evidencia radiográfica (Anexo I), ya que este tipo de estudio de gabinete permite descartar muchas lesiones que pueden ser tratadas en un primer o segundo nivel sin necesidad de cirugía, lo cual permitirá que los servicios de atención sean más eficientes al hacer los envíos a las unidades correspondientes.

\section{Conclusión}

El síndrome doloroso lumbar se caracteriza por dolor que compromete estructuras osteomusculares y ligamentarias. Su etiología es múltiple. Puede considerarse en fase aguda cuando el cuadro es de menos de 6 semanas de evolución, y en fase crónica cuando va más allá de ese período.

El programa de aplicación de las GPC permite eficientar la necesidad que tiene el sistema de salud mexicano, al momento que el médico de primer nivel atiende a un paciente con un síndrome doloroso lumbar. En primera instancia, el médico de primer nivel realiza el diagnóstico topográfico enfocado a la localización de la molestia por la que acude el paciente. Esta guía da el segundo paso, brindando los instrumentos necesarios para realizar un diagnóstico sindrómico. A la vez, se pretende lograr una correcta contrarreferencia en los pacientes posquirúrgicos cuando sean enviados de tercero a segundo nivel, y a su vez cuando sean contrarreferidos de segundo a primer nivel, para la correcta actuación del médico de primer nivel como estabilizador de la atención medica de los tres niveles de atención.

Este programa tiene el objetivo de que en la atención médica de primer contacto sean detectadas las llamadas "banderas rojas», que son signos o síntomas específicos y que orientan a un diagnóstico sindrómico, el cual se presenta con una guía de colores para su fácil identificación:

- Color verde: traumático.

- Color rojo: degenerativo.

- Color azul: síndrome de destrucción vertebral.

- Color anaranjado: deformidades (dolor neuro pático).

A partir de la correcta identificación de los signos clínicos y de las imágenes radiográficas, así como del reforzamiento en la actualización de la educación de los médicos familiares, se podrá eficientar la atención de la patología de la columna lumbar, identificando, tratando y enviando de manera oportuna a los pacientes a los diferentes niveles de atención, lo cual acortará los tiempos de espera de una consulta de especialidad y los tiempos prolongados de incapacidad, abatiendo indicadores que afectan enormemente la economía de los servicios de salud.

\section{Responsabilidades éticas}

Protección de personas y animales. Los autores declaran que para esta investigación no se han realizado experimentos en seres humanos ni en animales.

Confidencialidad de los datos. Los autores declaran que en este artículo no aparecen datos de pacientes.

Derecho a la privacidad y consentimiento informado. Los autores declaran que en este artículo no aparecen datos de pacientes.

\section{Financiamiento}

No se recibió ningún apoyo financiero en la realización de este estudio.

\section{Conflicto de intereses}

Los autores declaran no tener ningún conflicto de intereses con respecto a este artículo.

\section{Bibliografía}

1. Manchikanti L. CBT for low-back pain in primary care. Lancet. 2010;375: 869-70.

2. Smuck M, Kao MC, Brar N, Martinez-Ith A, Choi J, Tomkins-Lane CC. Does physical activity influence the relationship between los back pain and obesity? Spine J. 2014;14:209-16.

3. Covarrubias-Gómez A. Lumbalgia: un problema de salud pública. Revista Mexicana de Anestesiología. 2010;33(Supl 1):5106-9.

4. Chou R, Qaseem A, Snow V, Casey D, Cross JT, Shekelle P, et al. Diagnosis and treatment of low back pain: a joint clinical practice guideline from the American College of Physicians and the American Pain Society. Ann Intern Med. 2007;147(7):478-91.

5. Pérez I, Alcorta I, Aguirre G, Aristegi G, Caso J, Esquisabel R, et al. Guía de Práctica Clínica sobre Lumbalgia Osakidetza. GPC 2007/1. Vitoria-Gasteiz.

6. Cárdenas RU. Dolor lumbar: una aproximación general basada en la evidencia. Univ Med Bogota (Colombia). 2008;49:509-20.

7. Diagnóstico, tratamiento y prevención de la lumbalgia aguda y crónica en el primer nivel de atención. México: Instituto Mexicano del Seguro Social; 2009. Disponible en: http://www.imss.gob.mx/profesionales/ guiasclinicas/gpc.htm

8. Denniston PL, editor. Official disability guidelines. $11^{\text {th }}$ ed. Encinitas, California: Work Loss Data Institute; 2005. 
Anexo

\begin{tabular}{|l|r|r|}
\hline Sintomatologia Clinica & Si|No \\
Disestesias miembros pélvicos \\
Dismiución de la fuerza muscular \\
Reflejo Patelar y Aquileo \\
Signo de Bragard
\end{tabular}

Anexo 1. Aplicación de las guías de práctica clínica para el síndrome doloroso lumbar (lista de comprobación). 